\title{
INTERVENÇÃO DO ESTADO NA PROPRIEDADE DE REDES DE INFRA-ESTRUTURA'
}

\author{
Thiago Marrara \\ Mestrando em Direito do Estado pela \\ Faculdade de Direito da Universidade de São Paulo. \\ Analista Acadêmico.
}

\begin{abstract}
Resumo:
O presente artigo analisa os pressupostos de intervenção do Estado, especialmente pelos entes políticos locais, na propriedade de redes de inlra-estrutura. Assim, a primeira parte trata dos problemas jurídicos decorrentes destes objetos nas diversas áreas do Dircito e a segunda, aborda a questão da lunção social e sua aplicação às redes. Com bases nestes dois pressupostos, debate-se a intervenção em sede de conclusão.
\end{abstract}

\begin{abstract}
:
This article brings two reasons by which State, specially by its local spheres, should intervene on the property of inlra-structure networks used for rendering services. In this line, the first part of the article describes legal problems stemming from these networks and, the second, tries to depict what would be a social function for networks. On theses two arguments, public intervention is debated at the end.
\end{abstract}

Unitermos: propriedade de redes de infra-estrutura; intervenção do Estado; lunção social da propricdade.

\section{Introduş̧ão}

A estrutura e o objetivo do presente ensaio é bem simples: abordar dois pressupostos de uma pretensa intervenção do Estado, principalmente pelos Municípios, na propriedade de redes de infra-estrulura.

A primeira parte busca medir o potencial de conflituosidade das redes (primeiro pressuposto) por meio de uma análise de diversos problemas jurídicos e sociais que tais objetos suscitam. Trata-se, pois, de um cstudo indutivo.

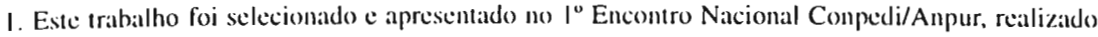
em novembro de 2(0)3, em Angra dos Reis/RJ. 
A segunda parte, por sua vez mais dedutiva, debruça-se sobre a possibilidade c a medida da função social das redes de infra-estrutura (segrundo pressuposto).

Em sede de conclusão, reconhecida a validade das conclusões oriundas das duas abordagens emprecndidas, algumas observações sobre a intervenção do Estado na propricdade de redes de infra-estrutura são oferecidas.

\section{Implicações jurídicas das redes de infra-estrutura}

\section{I Outorga onerosa de uso de bem público}

A mais recente implicação das redes de inlra-cstrutura $\mathrm{cm}$ tcrritório brasilciro remonta o problema sobre o uso do domínio público, que se amplia a partir de meados da década de 1990.

Na origem deste cmbatc, vislumbra-se a ampliação das redes, principalmente a partir do programa de desestatização brasilciro, do qual um dos objetivos cra renovar c ampliar as infra-estruturas nacionais (nos termos da Lei $n$. 9.491/97, art. 1", IV). O movimento de reforma administrativa, seguindo essa linha, inicia a transferência para os agentes particulares da prestação de serviços públicos essenciais, como os serviços de energia clétrica, telelonia lixa c gás canalizado.

Em que pese a cdição de normas de compartilhamento de infra-estrutura, tanto a atividade cconômica, quanto a prestação de serviços públicos, particularmente os privatizados, geraram um aumento significativo de demanda pelo uso de bens públicos, principalmente do domínio urbano e também das faixas de domínio componentes do sistema rodoviário.

Este acréscimo de demanda acabou ocasionando diversos conllitos que cram, anteriormente, incxistentes na medida que os entes políticos relacionavam-se $c$ negociavam entre si pelo uso de bem público de uns pelos outros, haja vista que eram esses mesmos entes os detentores dos bens e os interessados no seu uso.

Diferentemente, no momento atual, os detentores dos bens públicos são ora agentes públicos, ora particulares. Mais que isso, os interessados na utilização dos hens públicos, geralınente para instalação de redes de infra-estrutura, são entes eștatais, das mais diversas esferas políticas, ou agentes particulares, por vezes, concessionários c permissionários de serviços públicos lederais, cstaduais ou municipais.

Nessa modificação de cenário, com a privatização dos serviços públicos c a ampliação de atividades econômicas, c tendo cm vista a quantidade de novos atores, especialmente particulares, tanto os Municípios, quanto os agentes privados detentores 
de infra-estruturas, imediata e oportunamente começaram a exigir contraprestações pecuniárias pela outorga de uso. ${ }^{2}$

A sede por novas fontes de receitas municipais e a busca do lucro pelas administradoras de rodovias, num primeiro momento, alargou, como nunca, a discussão sobre o uso de bens públicos para a instalação de redes de infra-estrutura, vinculadas ou a prestação de serviços públicos ou ao exercício de atividades particulares. Os Municípios, especialmente, buscaram incrementar suas receitas financeiras ora pela instituição de taxas, ${ }^{3}$ ora por meio de preço público, como contraprestação pelo uso do bem público municipal, incluindo os bens de uso comum do povo. ${ }^{+}$

Quanto ao assunto, Di Pietro sustentou que os bens públicos são a própria expressão de uma função social e, por isso, eles devem colaborar para a ampliação dos benefícios à coletividade, servindo ao número de modalidade de uso que forem compativeis com sua destinação precípua e conservação. ${ }^{5}$ A lógica que deveria guiar o uso de bens públicos para instalação de redes de infra-estrutura, especificamente por concessionárias de serviços públicos, é a mesma que aparece na cessão gratuita de bens imóveis para entidades educacionais, culturais ou de fïnalidades sociais (nos termos do Decreto-Lei n. 9.760/46) e na ocupação gratuita de faixas de domínio, terrenos de domínio público e outros bens por redes de transmissão e distribuição de energia elétrica. Se existe uma mesma razão, deveria haver, por analogia, o mesmo direito.

Fora isso, questiona-se se o princípio da modicidade das tarifas, previsto no art. $6^{\circ} \mathrm{da}$ Lei de Concessões autorizaria as cobranças. Isto porque a receita decorrente das cobranças teria como contrapartida a elevação de tarifas, no caso, de outros serviços públicos, em detrimento dos cidadãos.

Conexas ao assunto, são igualmente as questões sobre o tipo de mecanismo jurídico-administrativo de outorga de uso mais adequado às atividades que

2. Inaugurando doutrinariamente a discussão, Adilson de Abreu DALLARI defende a viabilidade da cobrança pelo uso do domínio público municipal. V. Uso do espaso urbano por concessionárias de servigos de telecommanicaşäes. RDA, Rio de Janeiro: Renovar, v. 223, jan./mar. 2001. Mais tarde, Maria Sylvia Zanella DI PIETRO escreve em sentido oposto, opinando pela impossibilidade da outorga onerosa de uso. V. Parcerias na administração pública. São Paulo: Atlas, 2002, p. 341 et seq.

3. A taxa de serviço público é obviamente descabida na hipótese, restando, para discussão, um ınodelo de taxa de polícia, que, como categoria, faz bastante sentido se considerarmos as implicações ambientais e urbanísticas das redes de infra-estrutura, ou seja, a necessidade de controle das redes em convivência.

4. Se o uso comnum dos bens públicos, em quaisquer de suas categoriais, pode ser reınunerado, muito ınais o uso privativo - é o que se interpreta do art. 103 do Novo Código Civil.

5. Cf. Di Pietro, Maria Sylvia Zanella. A gestão juridica do patrimônio imobilicirio do Poder Püblico. Cadernos Fundap, São Paulo, ano 09, n. 17, dezembro, 1989, pp. 55-66. 
se pretendem realizar sobre o bem. Nesse tocante, aliás, Di Pietro manifestou clara oposição aos tradicionais Termos de Permissão de Uso (TPU), utilizados por diversas Prefeituras brasileiras.

O fato é que todas essas controvertidas questões estão, ainda, sub judice, inclusive no tocante aos critérios de mensuração do valor pecuniário do uso dos bens no caso de instalação de infra-estrutura (custo médio ou custo marginal).

Os referidos conflitos, aqui, ilustram a problemática que circunda o tema das redes de infra-estrutura. Tais conflitos servem à reflexão sobre um sistema federativo cooperativo capaz de conformar pacificamente os interesses dos entes políticos e suas concessionárias de serviços públicos com os interesses dos entes detentores de infraestrutura e, o que é mais importante, com os interesses dos próprios cidadãos, os quais, por vezes, aproveitam o aporte de nova rede, mas, sempre, arcam com seus custos.

A cooperação dos entes políticos e agentes particulares, ou a ausência dessa cooperação, mostra-se essencial à tarefa de se apreender e dirimir a conflituosidade oriunda do império das redes de infra-estrutura, assimétricas, plurais e transcendentes das circunscrições políticas. Esse é um dos desafios do Direito brasileiro.

\subsection{Convivências de redes}

Os conflitos acima mencionados são conseqüência imediata da estrutura de competências dos entes políticos brasilciros, tal qual positivada na Constituição de 1988. Trata-se, pois, de um conflito de normas constitucionais e administrativas que acabam resvalando para o questionamento de fórmulas doutrinárias, consagradas, de alguns institutos jurídicos.

No entanto, existem outras categorias de conflitos geradas por redes de infraestrutura e que decorrem, principalmente, do aspecto físico, estrutural, geográfico e funcional dessas coisas coletivas. São dignos de nota os problemas de convivência de redes, de acesso a redes e suas comodidades e, por que não, de crimes intermediados por elas.

Sobre esses conflitos, vejamos, de início, aqueles relacionados à convivência de redes, que tocam diretamente a normas urbanísticas e ambientais. As redes convivem não apenas com outras redes, mas, por se situarem em contextos urbanos c ambientais, interferem na dinâmica da vida dos cidadãos e diversos outros seres vivos.

No aspecto ambiental, de acordo com a lição de Ricardo Toledo Silva, podem ser citadas como implicações das infra-cstruturas: 1) a apropriação de recursos naturais, como a água utilizada pelas hidrelétricas, o gás natural, sem falar em outros 
recursos comuns, na acepção econômica do termo; 2) a poluição do meio físico, por cxemplo, pelos resíduos sólidos, gases poluentes e outras modalidades de poluição dilusa; 3) o agravamento de fenômenos naturais que envolvem grandes impactos ambientais e elevados custos sociais, tal como a elevação dos eleitos de inundações por conseqüência da impermeabilização de terrenos."

No lado urbanístico, acentuou Milton Santos, ${ }^{7}$ ao tratar da racionalidade do espaço, que os valores da utilização e da negociação das áreas urbanas são resultado dos objetos técnicos. O imperativo da competitividade acelera a modernização de certas partes da cidade em detrimento de outras. ${ }^{.}$

Diferentemente do que ocorre no campo, a cidade adapta-se mais dificilmente a essa lógica de produção e distribuição, de modernização e racionalização do espaço, uma vez que seus elementos constituintes, ou melhor, os bens que a estruturam, noladamente imóveis, são mais duráveis e menos llexíveis (daí sua rugosidade).

A rigidez dos agregados urbanos, com o avanço da tecnologia e com o desenvolvimento de redes adaptáveis, flexíveis e imateriais, não consegue reduzir c controlar efetivamente os mencionados reflexos urbanos da construção desses cquipamentos. A bem verdade, nem mesmo se deseja que a cidade se isole da evolução social e da influência das redes, pois elas também irradiam efeitos positivos, condicionando a dinâmica urbana, movimentando a cidade, sua produção, e oferecendo comodidades a seus habitantes.

Reconhecendo-se que as redes de infra-estrutura interferem negativamente na conjuntura ambiental e urbanística, mas que, de outro lado, são necessárias à consecução de objetivos desenvolvimentistas e à vida das cidades e seus ambientes, cabe-nos socorrer de mecanismos políticos e jurídicos aptos a conterem e conciliarem esses dois reflexos sociais.

6. Cf. Silva, Ricardo Toledo. Público e privado na oferta de infra-estrutura urbana no Brasil. Documento referente ao Dossiê Serviços urbanos. cidade e cidadamia, do Programa Interdisciplinar sobre Globalização Econômica e Direitos no Mercosul, GEDIM), disponível na página eletrônica da FAU USP, www.usp.br/fau. Cf. também do mesmo autor, Infiaestrutura urbana, necessidades sociais $e$ regulaş:ăo páblica, disponível na página eletrônica do Instituto de Pós-Graduação em Planejamento Urbano e Regional da Universidade Federal do Rio de Janeiro, hıtp://www.ippur.ufri.br/observatorio.

7. A nutureza do espaı̧o. São Paulo: Edusp, 2003, pp. 306-307.

8. Sobre o assunto, Toledo Silva afirma que "o poder indutor da infra-estrutura ou o condão desta cm criar novos valores imobiliários é objeto de controvérsia na literalura especializada... é discutível a relação de causalidade entre a valorização imobiliária c a oferta de infra-estrutura, pois csta pode ser subseqüente àquela. No entanto, independentemente da ordem que determina os processos, a concentração das inelhores ofertas etn áreas inais valorizadas tem um papel central na definição de desigualdade de acesso ìs capacidades de infra-estrutura" in Infra-estrutura urbana. 
No Brasil, os sistemas de regulação de serviços e atividades que emergem após a exaustão do modelo de oferta estatal nos anos 90 não são sulicientes para controlar e direcionar as implicações urbanas e ambientais das redes de infra-estrutura, restringindo-se aos seus aspectos econômicos. ${ }^{9}$ Desta forma, resta destinar aos próprios mecanismos da política ambiental essa função supra-setorial.

Entram em cena, então, os chamados Estudo de Impacto Ambiental (EIV) e o Estudo sobre Impacto de Vizinhança (EIA). Por meios desses mecanismos, verificase, previamente, a viabilidade da construção e da permanência das redes em um ambiente definido em prol da convivência dos elementos técnicos e humanos.

De acordo com a Resolução n. 01/86 do Conselho Nacional do McioAmbiente (Conama), os oleodutos, gasodutos, minerodutos, troncos coletores e emissários de esgotos sanitários, bem como as linhas de transmissão de energia elétrica c as obras hidráulicas para exploração de recursos hídricos, para que possam ser construídos, devem submeter a uma Avaliação de Impacto Ambiental (AIA), que nada mais é do que um instrumento similar ao EIA. ${ }^{10}$

Não se sabe, entretanto, em qual medida todas as redes de infra-estrutura se submetem aos estudos de impacto ambiental. Certo é que, envolvendo grande potencialidade de risco ambiental, seus pretensos construtores deverão comunicar-se com os órgãos do Sistema Nacional do Meio-Ambiente, evitando complicações futuras.

De outro lado, em vista do Estudo de Impacto de Vizinhança (EIV), consagrado no Estatuto da Cidade, em 2001, a realização de alguns empreendimentos, públicos ou privados, dependerão da elaboração de estudos prévios sobre seu impacto urbano, incluindo os efeitos relativos ao adensamento do tráfego e populacional, à proteção da paisagem urbana, ao patrimônio natural c cultural. Assim, para que possam obter licenças de construção, ampliação e funcionamento, expedidas pelo Poder Público Municipal, o empreendedor dependerá das conclusões dos referidos estudos.

Naturalmente, uma rede de infra-estrutura traz um potencial poluidor

9. Ricardo Toledo SiLva, Infra-estrutura ublana (...). No texto do autor, nota-se a razão de falarmos em problemas de convivência de redes: "De fato existe uma possibilidade de domínio territorial sobre a cidade e a regiāo, da parte de agentes privados, que não é enquadrável nas formas tradicionais de dominaçăo de mercados controlada pelos sistemas de defesa da concoriência. Mas seus efeitos podem ser determinantes na criação de áreas privilegiadas e na dominạ̧āo de um 'mercado' de produção da cidade, que, mais do que a dominaçäo sobre segmentos especifficos da ecomomia afeta a vida de toda a coletividade urbana. De maneira anciloga define-se a pertinência da infra-estrutara e dos serviços em rede ao sistema de regulaçäo ambiental, dado que a maioria deles envolve interaşäes e impactos relevantes amm o meio ambiemte natural e comstruído"

10. MilarÉ, Édis. Direito do ambiente. São Paulo: Revista dos Tribunais, 2001, p. 315. 
que acaba por relacioná-las diretamente aos bens tutelados pelas normas ambientais e urbanísticas em questão, de modo que sua construção deve-se sujeitar aos ditos instrumentos.

Aliás, nos termos do art. 60 da Lei n. 9.605/98, que trata das sanções ambientais, qualquer construção, reforma, ampliação de obra potencialmente poluidora que contrarie norma legal ou regulamentar, esteja ou não licenciada ou autorizada, sujcita seus responsáveis a sanções penais.

O respeito à prévia elaboração de estudos de impacto de vizinhança $\mathrm{e}$ de impacto ambiental (já que não se excluem, por força legal) é condição imprescindível para o aperfeiçoamento de um modelo de convivência de redes que maximize as vantagens que essas infra-estruturas podem proporcionar, afastando conflitos humanos e técnicos. Contudo, os responsáveis por esses bens, às vezes sob a conivência das Municipalidades, " têm ignorado esses instrumentos e os bens jurídicos respectivos.

\subsection{Acesso necessário a redes de infra-estrutura}

Como já se afirmou, as redes de inlira-estrulura são instrumentos necessários mais à circulação, que à produção. No mundo contemporâneo, a busca de Muidez, o objetivo de se atingir a maior eficiência da circulação de bens e serviços projela-se sobre as redes de infra-estruturas, determinando seus caminhos, suas localizações, suas conexões e suas grandezas. A geografia das redes, destarte, nada mais é que a projeção dos interesses dos agentes da oferta, produtores e fornecedores, cstatais e particulares.

As redes de infra-estrutura naturalmente são aliadas importantes na busca de vantagem comparativa para esses agentes econômicos. ${ }^{2}$ Pela força circulatória que lhes é peculiar, somada aos altos custos empresariais de construção que geram e, por vezes, pela impossibilidade de serem duplicadas, as redes são clementos que distinguem os agentes econômicos no lado da oferta.

II. A negligência dos Municípios quanto a urbanização em geral é notada por BoRis Fausto: “ $O$ Brasil enfienta os novos desafios em uma situação difical. Quase não é preciso lembrar que a opção pelo) crescimento desordenado e a concentraşäo de renda produziram efeitos sociais devastadores. A urbanizaşão, que em parte resultou no 'inchago'das grandes cidades, agravou problemas de transponrtes, de sameamento básico, da poluiģăo do ar etc". História do Brasil. São Paulo: Edusp, p.554.

12. Santos. M., A natureza do espaço, p. 268. 
Quem as detém, produz e distribui com mais facilidade; ou, não raro, somente quem as detém pode produzir ou prestar algum serviço. ${ }^{13}$

Por essas razões, as redes de infra-estrutura logo chamaram a atenção do Direito Econômico, especialmente nas searas do direito da concorrência c do consumidor. Como condicionante da livre-iniciativa (entendida como liberdade de compresa, trabalho e consumo) e da livre-concorrência, as redes não poderiam se afastar do princípio do acesso necessário, ou seja, não poderiam obstar o acesso de concorrentes a determinados mercados, nem tampouco o acesso de consumidores a comodidades.

Quanto ao acesso dos concorrentes, explica o professor Salomão Filho que "os ilícitos antitruste normalmente relacionados à conexão são os de recusa de contratar e discriminação entre concorrentes" "A Ainda seguindo a orientação do nobre jurista, note-se que a recusa de contratar, entendida como um ilícito, geralmente se verificaria em hipóteses de contratos de uso de redes que são repentinamente interrompidos. Desse modo, afastar a recusa de contratar, num sentido tradicional, não necessariamente soluciona todos os problemas relacionados ao acesso a redes.

De fato, não haveria ilicitude quando um detentor de rede de infracstrutura não permitisse o acesso de outros agentes econômicos (nem sempre concorrentes) a ela. Isto porque, não se pode lalar, no caso, de um dever de contratar, de ceder o uso da rede.

Em vista dessa situação, forjou-se, então, a doutrina da essential facility nos EUA. Segundo Pitofsky, ${ }^{15}$ tal tcoria foi consagrada em 1912 no caso "United States vs. Terminal Railroad Association" pelo qual os proprietários de redes ferroviárias foram obrigados a ceder o uso dessas redes a outras empresas do ramo. No mesmo sentido, a Suprema Corte Americana, decidiu nos casos "Associated Press vs. United States", de 1945, e no "Lorain Journal Co. vs. United States", de 1951. No

13. Por ınais que se enfatize a função pós-produção das redes, não ignoramos a essencialidade dessas infra-estruturas como requisito do processo de produção, que é fato histórico e a primeira razão de ser das redes. Veja-se essa última função no exemplo de Ricardo Toledo SILVA: " a história dos servị̧os de energia elétrica e gás nos EUA é marcada por uma expansão acelerada de oferta para o consumo, que estabeleceu uma relação de mútuo crescimento - e muitas vezes de ligas̆äo comercial - com a indisstria de eletrodomésticos" em Infra-estrutura urbana (...).

14. Salomào FILIIO, seinpre buscando conciliar as finalidades do direito da concorrência aos direitos do consumidor e outros princípios constitucionais, arrola o princípio do acesso necessário como un dos princípios gerais da regulação. A respeito, vale consultar sua densa obra Regulą̧ăo da atividade econômica - principios e findamentos juridicos. São Paulo: Malheiros, 200)1, p. 52 et seq.

-. 15. Sobre os julgados históricos referentes à teoria, cf.o artigo de PITOFSкY, Robert et al. The essential facilities under U.S. Antitrust Law". Antitrust Law Journal, v. 70, 2002, pp. 443-462. 
caso “Otter Tail Power Co. vs. United States", a teoria foi aplicada de sorte a permitir que revendedoras americanas locais utilizassem as redes de transmissão da Otter Tail para adquirir energia elétrica de outras empresas geradoras.

Com base na teoria da essential facility, a recusa de ceder acesso a redes de infra-estrutura ${ }^{16}$ resta ilegal sempre que essas redes sejam meios imprescindíveis à entrada de um agente no mercado. A teoria foi justamente construída para impedir monopólios naturais que se sustentassem sobre a propriedade, com exclusividade, de certas infra-estruturas. ${ }^{17}$

No entanto, seguindo Salomão Filho, mesmo essa teoria não seria apta a reduzir todos os conflitos de concorrência, uma vez que geralmente se permite que o detentor da rede escolha quais os concorrentes que poderão acessá-la - o que deixa entrever possíveis atentados à isonomia. ${ }^{1 /}$ Seria necessário, pois, que a rede fosse considerada como um verdadeiro bem público.

Ainda no Direito Econômico, mas, agora, aproximando-se do pólo consumidor, as redes de infra-estruturas levantam duas questões: a de universalização dos serviços públicos e a de liberdade de consumo.

Diferentemente do que ocorre na problemática do livre-acesso de concorrentes à rede e, conseqüentemente, ao mercado, não há, nesse aspecto, uma solução que desponte do direito concorrencial. ${ }^{19}$

No Brasil, mesmo com os avanços obtidos especialmente na década de 1970, sob o modelo de controle estatal das grandes infra-estruturas, não se conseguiu atingir uma verdadeira universalização das redes de infra-estrutura, marginalizando-se, no atendimento dos serviços públicos essenciais, principalmente a população periférica.

Essa situação se prolongou, ademais, em virtude da exaustão de fontes estatais de financiamento à infra-estrutura - problema que, em tese, deveria ser solucionado com investimentos privados, dentro do programa de desestatização da década de 90.

16. Note-se, a tempo, que a teoria não se aplica apenas a redes de infra-estrutura, mas "em $t o d o s$ os caso em que haja o controle pelo sujeito ativo de um meio de produçäo inprescindivel e insubstituível para a produção de um determinado bem final e seja tecnicamente e economicamente possivel coloci-lo à disposição do sujeito passivo", Salomāo Filho, ibidem, p. 53.

17. Afirma PITOFSKY que "the doctrine is one long-standing limitation on the general rule that a firm has no obligation to deal with its competitors. As stated by the Ninth Circuit in Alaska Airlines, Inc. v. United Airlines, Inc. "IT/he essential facilities doctrine imposes liability when one firm, which controls na essential facility; denies a second firm reasomable access to a product or service that the second firm must oblain in order to compete with the first" (ibidem, p. 446).

18. Op. cit., p. 56.

19. Por essa razão, Salomão Filho sugere que as respostas aos problemas de amplo acesso dos consumidores a redes de serviços públicos decorram de iniciativa estatal (ibidem, p. 59). 
Diz-se "em tese", porque a consecução de uma universalização efetiva passa, necessariamente, pela engenharia de um conceito de universalização satisfatório, não simplesmente pela imputação de uma obrigação de caráter genérico. Não há universalização pela simples existência de redes de infra-estrutura sobre determinado espaço territorial. Preleciona Ricardo Toledo Silva que a tarefa de se verificar a existência ou-não de redes sobre alguns espaços é tarela relativamente fácil, mas se saber exatamente se a qualidade e a quantidade das redes são suficientes para o fornecimento de serviços adequados é bem complexo. ${ }^{20}$

Por isso, a formulação jurídica de uma pretensa meta de universalização nem sempre configura um dever de universalizar o serviço em termos concretos. Na telefonia fixa, exemplifica o mesmo autor, as metas de universalização foram estabelecidas de modo geral, de sorte que se poderia cumpri-las pela duplicação de infra-estruturas em um mesmo lugar, de mais fácil e barata alocação, em detrimento das periferias. Bastaria a média de infra-estrutura instalada para se dizer cumprida a universalização.

Com isso, entre outras coisas, percebe-se que as políticas setoriais seguem muito mais objetivos de criar concorrência e proteger os agentes econômicos no lado da oferta, do que tutelar, em primeiro lugar, os direitos do cidadão-consumidor - mesmo porque nem sempre vigora a idéia de que a concorrência serve ao bem-estar geral.

Mecanismos supra-setoriais, destarte, são imprescindíveis ao controle de uma verdadeira universalização do lado da demanda por serviços viabilizados por redes de infra-estrutura. $O$ direito do consumidor, de um lado, deve-se aliar a outros mecanismos jurídicos, tais quais as contribuições de intervenção no domínio econômico, nessa função. Aí sim, talvez, se logre obter uma universalização que se demonstre, na estrutura capilar, capaz de atender aos direitos do cidadão. ${ }^{21}$

20. Explica o urbanista que "a medida que os sistemas vão se espalhando pela mancha urbana para atingir diferentes áreas, fica muito dificil estabelecer as condiçöes de acesso de cada área, pois aparentemente existe uma universalização de cobertura. Na realidade, entretanto, continua a existir unna grande diferenciação de qualidade e quantidade de acesso, para cujo controle se requerem sistemas de informação e acompanhlamento mais complexos que os anteriores"

21. Segundo Toledo Silva "As afromtas a direitos dos consumidores perpetradas pela Câmara de Gestão da Crise de Energia, ao longo da crise de 200l, tormaram públicon o papel central que o sistema de direitos do consumidor tem a cumprir no complexo institucional da regulação dos serviços públicos"

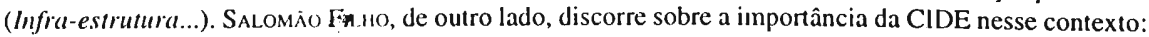
"o titular de direitos sobre as redes parte de uma imensa vantagem inicial. Essa vantagem pode proporcionar lucros extraordinários. Esses lucros podem ser compensados tanto por uma obrigașäo diretu de provimento de servigos a consumidores sem poder aquisitivo como pela instituiģão de uma contribuiçäo de intervensãa no domínio ecomômico" ibidem, p. 59. 
No entanto, tais questões ainda estão para ser equacionadas no novo modelo estatal que se constrói, servindo aqui, tais como as outras levantadas, para instigar a crítica e a revisão dos preceitos e institutos jurídicos envolvidos nas sociedades de redes.

\subsection{Cooperação internacional e jurisdição penal}

Talvez se possa afirmar que nada mais problemático, em escala global, ${ }^{22}$ que a questão da jurisdição sobre conflitos e crimes viabilizados por redes de infracstrutura. As redes internacionais, das binacionais às universais, derrubam as clássicas barreiras físicas, jurídicas e políticas de prevenção e repressão de ilícitos penais transnacionais.

Exemplo significativo disso se vê na ação ajuizada por uma associação de estudantes franceses contra Yahoo! Inc., prestadora de serviços de internet, para que csta interrompesse ou vedasse a prática de leilões virtuais de objetos de cunho nazista no território francês em vista de normas do Código Penal da França.

A oferta dos objetos ilícitos pode provir dos mais diversos países e, o que mais complica a situação, é que os leilões são colocados na rede pelos chamados provedores de conteúdo, que não se confundem com os provedores de serviço de internet. Em outras palavras, a oferta pode sair da Ásia, enquanto o leilão é organizado por um provedor de conteúdo na América do Norte e o objeto é comprado por um curopeu.

Nesta cadeia, o problema surge quando uma prática ilícita é comctida. Entra em cena, então, a pretensão punitiva dos Estados Soberanos, que pode ou-não ser ativada de acordo com o princípio de jurisdição penal adotado.

Apenas por aí já se percebem as influências que as redes de infra-estrutura globais exercem ou exercerão sobre, e principalmente, os critérios de fixação de jurisdição penal por Estados Soberanos. Tenha-se em mente, ainda, que não se trata apenas de um problema relativo às redes de telecomunicações, ou seja, redes de telefonia, tclevisão, rádio etc. A possibilidade de comissão de ilícitos por outros tipos de rede, como as de energia elétrica e saneamento, não é desprezível.

Com efeito, de um lado, o surgimento de novos crimes e conflitos via redes conduz à rediscussão da teoria da territorialidade objetiva de jurisdição, ou effects

22. Bem constatou Milton Santos que "as redes são os mais eficazes transmissores do processo de globalização a que assistimos”, ibidem, p. 266. 
doctrine, consagrada, em 1927, com o clássico caso Lótus (Turquia v. França) ${ }^{23}$ Essa regra de exercício de jurisdição, que autoriza um Estado a submeter às suas Cortes a análise de atos e condutas que produziram efeitos substanciais em seu território, ${ }^{2+}$ alarga a jurisdição penal de um Estado.

De outro lado, o fortalecimento c a consagração do princípio da jurisdição universal, ${ }^{25}$ fruto do princípio da solidariedade internacional, são visíveis. A respeito disso, basta verificar o que já laz a Bélgica, a Espanha e diversos outros países. ${ }^{26}$

Contudo, é de se questionar se a simples adoção de novos princípios de jurisdição penal seria suficiente para abafar as novas lontes de conflitos trazidas pelas redes. Tais princípios ampliativos de jurisdição esbarram lacilmente em outros institutos de Dircito Internacional e ocasionam, não-raramentc, contlitos de jurisdição entre Estados. Sendo assim, em muitos casos, pouco ou nada dessa nova conflituosidade poderão conter, restando igual ou maior o grau de impunidade de criminosos.

Veja-se, por exemplo, o que ocorrcu no caso Pinochet e no caso do "Arrest Warrant of II April 2000", julgado pela Corte Internacional de Justiça em 2002. Aqui, a Bélgica pretendia julgar o ministro de Relações Exteriores da República Democrática do Congo com base no princípio da jurisdição universal e sem a custódia do acusado, entre outras coisas. ${ }^{27}$ Scu pedido, porém, foi indelerido com base na imunidade de agentes olicciais à jurisdição penal estrangeira, cm prejuízo do princípio da universalidade da jurisdição penal belga.

Percebe-se, portanto, que mesmo a adoção de novos princípios de jurisdição penal, notadamente o princípio da universalidade e da territorialidade objetiva,

23. Neste caso, um barco francês chocou-se com um barco turco, levando à destruição deste último e à monte de turcos. A Turquia capturou, em seu território, os franceses e os julgou por homicídio. Levado o caso ao Tribunal Permanente de Justiça Internacional, foi reconhecido o exercício de jurisdição penal pela Turquia com base no princípio da territorialidade objetiva.

24. Brownle, Ian. Princípios de direito internacional público. Lisboa: Calouste Gulbenkian, p. 320.

25. A universalidade surgiu a fim de sufocar a pirataria e o tráfico internacional de pessoas. Sobre o princípio da universalidade de jurisdição, cf. o excelente artigo de RandaLl, Kenneth. Universal Jurisdiction! under imernational law. Texas Law Review, março, 1988, pp. 78.5-84I.

26. Alguns Estados utilizam o princípio da segurança, pelo qual se permitem julgar atos praticados em outros países, mas que afetam sua segurança. Os Estados Unidos e a Inglaterra, ainda que não expressamente, valeın-se amiúde do referido princípio. V. Brownlıe, lan. op. cit., p. 325.

27. Neste caso, a discussão sobre a aplicação de jurisdição universal foi levantada, inas não levada adiante pelo Congo. São dignas de conferência, não obstante, as opiniōes dos ininistros ReSEK e GUILLAUME a respeito da jurisdição universal. $O$ julgamento foi plenamente favorável à República Democrática do Congo com fundamento na imunidade dos agentes oficiais à jurisdição penal estrangeira. A Bélgica foi obrigada a anular o mandado de prisão expedido. 
não se mostra tão eficiente para um ambiente de redes mundiais. Haveria melhor solução!?

Na medida em que um Estado não pode opor normas de direito interno à aplicação de normas internacionais e à responsabilidade que delas decorre, ${ }^{2 \times}$ a busca de um sistema internacional, ainda que plurilateral, de novas prescrições sobre ilícitos instrumentados por redes de infra-estrutura é um possível caminho. A vantagem, aqui, ć a ausência de conflitos de jurisdição em virtude da existência de um único sistema normativo penal, internacional, ao qual todo Estado está vinculado.

Em suma, tudo isso serve apenas para demonstrar como a fluidez de dados c objetos, via redes de inlra-estrutura, c a potencialização de novas modalidades criminosas além-Ironteiras, oriundas deste novo contexto mexe, diretamente, com as clássicas concepções dos sistemas normativos penais e internacionais.

\subsection{Responsabilidade extracontratual e planejamento}

Depois de exemplificar alguns conflitos característicos de um ambiente social que se constrói e se reproduz por meio de redes de intra-estrutura, afigura-se pertinente, por derradeiro, tecer alguns comentários sobre a responsabilidade extracontratual sobre danos oriundos do plancjamento estatal, suas omissões e modificações. ${ }^{29}$

As questões relativas principalmente à convivência e compartilhamento de redes de infra-estrutura exigem que o Poder Público lance mão de uın conjunto de normas capazes de ordenar essas infra-estruturas dentro de um dado espaço geográlico.

O plancjamento, em breves palavras, é o mecanismo capaz de dirimir diversos conflitos conexos à proliferação das redes, entre eles: 1) a danificação desses objetos em virtude de obras de instalação de outros; 2) a poluição dos ambientes em que elas se instalam; 3) a exaustão do espaço físico que ocupam; 4) os prejuízos à scgurança dos cidadãos, benelïciários de suas comodidades ou-não; 5) a exaustão de sua capacidade funcional, $\mathrm{cm}$ aspectos quantitativos ou qualitativos etc.

Todas as três esteras políticas não poderiam se omilir no plancjamento necessário a dirimir os conflitos mencionados por decorrência direta do princípio da

28. V. Convenção de Viena sobre o Direito dos Tratados, 1969, art. 27, e a Resolução n. 83 da 56 a. Sessĩo da Assembléia Geral da ONU, 2002, que Irata sobre Responsabilidade dos Estados, art. 32.

29. V. Figueiredo, Lúcia Valle. O devido processo legal e a responsabilidade do Estado por dano decorrente do planejamento. Revista Diálogo Jurídico. Salvador: CAJ - Centro de Atualização Jurídica, n. 13, abril-maio, 2002. 
indisponibilidade do interesse público, primário, e da obrigatoriedade do planejamento para o setor público, nos termos do art. 174 da Constituição da República. Por mais que não se trate de redes públicas, administradas direta ou indiretamente, e sim de redes particulares, o Administrador Público não resta autorizado a ignorar o plancjamento - como tem feito algumas Administrações - sob o risco de responsabilização judicial.

No Brasil, a responsabilidade do Estado já estava consagrada na Constituição de 1824, mas recaia sobre o funcionário público - na primcira Constituição da República, de 1891, da mesma forma. Nas Constituições de 1934 e 1937, em notória cvolução, previu-se a responsabilidade solidária entre funcionário e Estado. Enfim, a partir da Constiluição de 1946, consagrou-se a responsabilidade objetiva do Estado, assegurado o dircito de regresso contra o luncionário, cmbora se levando $\mathrm{cm}$ consideração, aqui, a existência de culpa ou dolo. A responsabilidade objetiva loo mantida na Constituição de 1967, inclusive com a reforma de 1969, e também na de 1988 , no art. 37, § 6".30

A responsabilidade objctiva do Estado supcra a teoria da distinção entre atos de gestão e atos de império, forjada no Direito Administrativo sob a influência civilista. Baseando-se simplesmente na existência do dano e do nexo de causalidade e independente da licitude ou ilicitude da atuação estatal, a responsabilidade extracontratual do Estado chega a fulminar a insindicabilidade dos atos administrativos discricionários, atingindo tanto atos exercidos, sob função legislativa, quanto sob a jurisdicional (cm que a liberdade de escolha dos agentes públicos é ampla).

Sendo assim, parece não subsistir óbices à responsabilização do Estado por danos decorrentes de malplancjamento ou não-planejamento das redes, conlorme atestam alguns julgados trazidos à colação: 1) "a falta de cuidado na realização de obras em lugar que sabidamente deveria haver rede de água caracteriza a responsabilidade pelos danos causados nos encanamentos" (RT 612/ 73); 2) "prédio construído sobre galeria de águas pluviais - planta aprovada pela Municipalidade - danos causados a casa por essa galeria - obrigação de indenizar" (RT 372/171).

Deve-se fazer ressalva, contudo, à impossibilidade lógica, sustentada por Valle Figuciredo, de se aplicar a responsabilidade objetiva no caso de omissão da

30. Sobre o assunto e boa jurisprudência, vide CallaLI, Yussef Said. Respon.sabilidade civil do Extudo. São Paulo: Malhciros, 1995, p. 28 et seq. 
Administração Pública. ${ }^{31}$ Nesta hipótese, a jurisprudência tem-se firmado pela averiguação de culpa ou dolo da Administração, tratando-se de responsabilidade subjeliva.

A csse respeito, são ilustrativos os casos de enchentes e inundações, principalmente aquelas ocorridas na vářea do rio Tamanduaté́, na cidade de São Paulo. Por se tratar de responsabilidade por omissão, desde que provada a lalha da Administração em tomar medidas de prevenção às previsíveis enchentes na região, as indenizatórias são, via de regra, julgadas totalmente procedentes, em desfavor não apenas da Municipalidade, mas, por vezes, do próprio Estado de São Paulo, de cujo domínio o referido rio laz parte (RT 528/74; 530/70; 601/67 etc.).

Mais interessante, nesses casos, ć a indiferença de alguns julgados do Tribunal paulista em relação à instalação de moradores nas zonas reconhecidamente sujeitas a inundações freqüentes - que serve bem de analogia ao problema de instalação de redes. Nesse sentido, "mesmo que as construções fossem posteriores às inundaçōes, tal não libera a Municipalidade da obrigação de indenizar os prejuizos, pois deveria obstar edificação na região, negando on exigindo requisitos de segurança específicos; licenciado a edificação, deve suportar os prejuizos que a deficiência dos serviços puiblicos vem acarretando" (RT 544/93). Da mesma forma devem agir os entes públicos cm relação à instalação de redes, sob o risco, cnorme, de sucumbirem às indenizatórias.

Isso, portanto, revela o quão necessário é o planejamento público relalivo à instalação e funcionamento das redes de infra-cstrutura.

Enfim, nem se diga que os detentores das redes de infra-estrutura, ainda que de interesse restrito e estritamente particular, são menos suscetíveis a responsabilização por eventuais prejuízos causados à coletividade ou a cada um, individualmente, pelo desacordo dos ditos bens ao planejamento estatal.

Bem provavelmente, tais agentes, notadamente empresas, não poderiam ser condenados com fundamento no art. 174 da Constituição da República, pelo qual o plancjamento é indicativo para os particulares (não-compreendidos aqui os proprietários de redes como bens reversíveis em contratos de concessão de serviço).

Malgrado a validade do argumento, na prática, a sujeição ao planejamento parcce inexorável, basicamente por dois motivos. Em primeiro lugar, uma possível responsabilização derivaria mesmo de dever que recai sobre o controlador das sociedades

31. Explica a administrativista que, "se o Estado omitit-se, hi de se perquirir se havia o deves de

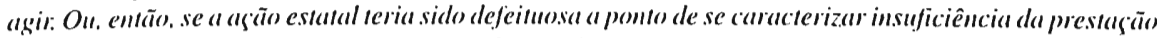
de servi(o). Näo há como provar a omissão do Estado, sem antes comferir se houve "fatule de service". É dizer: näo ter funcionado o servigo, ter funcionado mal ou kardiamente", p. 09. 
cmpresariais e que consiste na obrigação de conduzir as atividades empresariais cm consonância, senão $\mathrm{cm}$ busca indireta, dos interesses coletivos. ${ }^{32}$

Note-se bem que se fala em dever "do controlador" consoante o art. I 6, parágrafo único, da Lei n. 6.404/76, pois é esse que efetivamente coordena o modo de produção, dispondo os bens de produção de uma lorma ou outra com vistas aos objetivos que orientam a grande cmpresa.

De outro lado, lembre-se de que as redes requerem suportes territoriais, ainda que sejam constituídas simplesmente por nós, por coisas materiais que se translormam em redes pela atuação de coisas imateriais (como as redes de telefonia celular, por exemplo). Assim, na medida $\mathrm{cm}$ que buscam instalar tais elementos concretos, as empresas necessariamente se submetem às limitações administrativas que a Administração Pública pode impor sobre scu domínio público. Não se as respeitando, ou-não se formará a rede, ou, já formada, buscar-sc-á responsabilizar o controlador da cmpresa.

Portanto, não-obstante a inaplicabilidade do art. 174, as redes particulares estarão condicionadas pelo plancjamento público $\mathrm{cm}$ lunção da norma que vincula o controlador a direcionar a cmpresa consoante os objetivos da coletividade $\mathrm{c} c \mathrm{~m}$ razão das limitações administralivas que recairão sobre essas redes no momento $\mathrm{cm}$ que sc instalarem sobre delerminado espaço geográlïco.

As faltas dos entes públicos e das empresas privadas na claboração e no cumprimento de um planejamento podem, sem qualquer sombra de dúvida, impularlhes a responsabilidade por danos causados à coletividade e aos indivíduos como conscqüência da construção c do funcionamento das redes.

\section{Algumas funções sociais}

Levantadas algumas das mais variadas implicações jurídicas lomentadas pela dinâmica e pela cstática das redes de infra-estrutura, inicia-se, a partir daqui, um breve escorço sobre a idćia de função social que permeia a propriedade em geral e, por conseguinte, a propriedade das redes. Ao se vencer essa próxima elapa, será cabível tratar, cm sede de conclusão, da intervenção cstalal sobre csses objetos.

32. Aduz Comparato que, "em se tratando de bens de produciāo, o poder-dever do propriencirio de dar à coisa uma destinaf̧äı compatível com o interesse da coletividade transmuda-se, quando tais bens sĩo incomporados a uma exploraşão empresarial, em poder-dev'er do titular do comtrole de dirigiv a empresa para a realizașāo dos interesses coletivos" Cf. A funşão social dos bens de produscäo. Revista de Dircito Mercantil, Industrial, Econômico e Financeiro, n. 63, julho-setembro, 1986, p. 76. 


\section{I Função social da propriedade}

"Atualmente tornou-se lugar comum dizer que a propriedade é uma funşão social; há algo de verdade nisso, porque a ação do proprietário, hoje em dia, éstá muito mais circunscrita que sob o individualismo extremado do século XIX (...)" "3. Esta frase, nas entranhas do brilhante ensaio de Del Nero, resume bem o lugar que ocupa a lunção social da propricdade nos ordenamentos jurídicos atuais.

Da função social da propricdade decorreram outras tantas funções sociais diversas, variantes, c que também interessam imensamente à missão de analisar as redes de infra-estrutura. Incluem-se aí as funções sociais dos bens de produção e da cidade, por exemplo.

No fundo, contudo, parece que todas as ditas três funções são uma só: a dos bens de produção como especificação da primeira; c a da cidade, como cxtrapolação, a medida que se constrói como somatória da função social dos bens públicos e privados no grande palco das interações humanas, a cidade.

Justamente por essa razão, não seria prudente tratar de variantes da lunção social da propriedade, sem antes rever a evolução de seu objeto de qualificação, qual seja, a propricdade.

Sucintamente, numa perspectiva histórica, a propriedade privada cstruturou-se $\mathrm{cm}$ três estágios, partindo da propriedade coletiva, marca do sistema fcudal. À aparição da possessio naturalis (detenção ou corpus) seguiu-se o reconhecimento, pelo Dircito, da possessio civilis, i.e., da posse jurídica, e, enfim, consagrou-se o domínio, garantindo aos indivíduos o controle pleno sobre um bem. ${ }^{3.4}$

Em movimento ondular, a crista da propriedade coleliva, na Idade Média, contrapõe-se a da propriedade privada como expressão da personalidade humana, no século XIX. A partir da Primeira Grande Guerra, o movimento se reverte. Daí cm diante, em modo regressivo - mais nos regimes socialistas e menos nos ocidentais capitalistas - a propriedade assume uma função socialmente utilitária. ${ }^{35}$

33. Dre Nero, João Alberto Schützer. O significado juridico da expressão "fingrão social da propriedede", Revista da Faculdade de Dircito São Bernardo do Campo, v. 3, 1997, p. 85. Adiciona o autor, em brilhante síntese do pensamento da questão, que "(...) a decadência das antigas concepsōes é muito mais acentuada quanto ao direito subjetivo de propriedade: ele é comtido em nome do interesse geral. despedagado em favor dos asuarios da coisa, atucado por todos os lados e, portanto, destroma-se " proprientirio, que deixa de ser o que parecia - momarca absoluto e imiolável (...)"

34. Del Nero, ibidem, p. $87 \mathrm{ct} \mathrm{seq.}$

35. A influência das guerras sobre a propriedade é inegável e, explicitamente, aceita pelos ordenamentos jurídicos. Vejam, como exemplo, as exceções que se abrem, no sistema constitucional tributário, para os 
Este regresso à idéia de propricdade coletiva, contudo, não significou o af astamento da autonomia do proprictário sobre seu objeto, mas sim a criação de uma nova facela do direito de propriedade. ${ }^{36}$

A propriedade passa a se equilibrar sobre uma díade principiológica: a liberdade individual c a função social, conforme Del Nero. Ao nosso ver, estaria aí uma indircta confirmação da tcoria sociológica positivista de Duguit, que vislumbrava uma tendência de socialização da propricdade scm colctivização. ${ }^{37}$

Com o passar do século XX, o movimento ondular não mais serviria para explicar a propricdade. Melhor seria falar de uma estabilização do conceito sobre ou entre duas linhas paralclas, uma do Dircito Privado e outra, do Público. Assim, de um conceito feudal coletivo para um conceito liberal privado, que se sucederam como extremos contrapostos, a propricdade, hoje, parece residir no meio das duas concepções, das duas linhas, ${ }^{3 \times}$ evidenciando a tcoria do grande publicista francês, e a díade principiológica que mencionou o civilista brasileiro.

No Brasil, o reflexo dessa movimentação se fez sentir no ordenamento jurídico com a Constituição de 1946, cm que se previu a desapropriação por interesse social. Mais tarde, a expressão "lunção social” propriamente dita, entrou nesta Carta por mcio da Emenda Constitucional n. 10/64, que incluiu alguns parágrafos ao art. 147 - dispositivo este referente ao princípio da justa distribuição da propriedade. A Constituição de 1967, por sua vez, reconheceu a função social como um dos princípios da ordem econômica e social, mas a concentrou sobre a propriedade rural. Por lïm, a Constituição da República de 1988, previu a função social em diversos dispositivos (arts. 5", XXIII, e 170, III; c, mais especificamentc, nos arts. 182, $\$ 2 "$, c 186). ${ }^{30}$

Apesar das previsões constitucionais c das cvoluções doutrinárias, na verdade, não se sabe exatamente qual o sentido deste novo caráter público, social, mas

empréstimos compulsórios e impostos extraordinários em casos de guerra ou sua iminência, previstos, respectivamente, nos arts. 148, J e 154, II, da Constituição da República de 1988.

36. Essa proposição se restringe aos sistemas romano-germânicos e anglo-saxônicos. Segundo D,

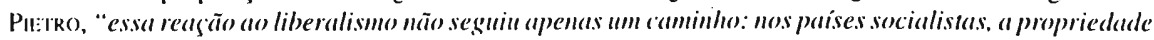
prisada fori abolida..." in $A$ géstão juridica do patrimônio imobiliário do Poder Pablico, p. 56.

37. DI:L. NERO, ibidem, p. 88.

38. Mais uma vez, é isto que laz cada vez mais tênue e difícil a distinção entre institutos de direito público e de direito privado. Veja-se, por exemplo, o que ocorte na concessāo, que se equilibra entre o interesse privado do lucro e o interesse público da atividade prestada, conforme insiste DI PIETRO em suas obras.

39. Di PIETro, A gessão juridica do patrimônio imobilicírio do Poder Páblico, pp. 56-57. 
não-coletivo, da propricdade. Certo apenals é que se convencionou denominá-lo "função social" restando aos doutrinadores e ao legislador a tarela de esclarecer se se trata de um novo fundamento fillosófico para o dircito de propriedade; uma nova estrutura deste dircito ou, enfim, um novo método de interpretação do direito da propricdade.

Na falta de um sentido claro e limitado do que venha a ser "lunção social" desenvolveram-sc, então, os mais diversos cstudos c teses, dos quais vale mencionar os referentes à função social dos bens de produção e dos bens de acesso, o da função social dos bens públicos, e o da função social das cidades.

Assim, mais fácil será encontrar uma forma de afirmar e delimitar a lunção social das redes de infra-estrutura, depois de compreender, minimamente, essas outras lunções sociais.

\subsection{Função social dos bens de produção e bens de acesso}

Comparato, cm scu artigo clássico, supramencionado, propôs-se a tratar da função social a partir de uma análise mais econômica dos bens físicos. Na visão do exímio comercialista, o advento da sociedade industrial c a lixação de um padrão de produção $\mathrm{cm}$ larga escala, voltado para um mercado de massa, impuscram a distinção entre bens de produção e bens de consumo em detrimento de outras calcgorizações.

Referida classilicação, que se move por um critério de destinação do hem, permite que tanto os móveis quanto imóveis sejam enquadrados na idéia de bens de produção, assim entendidos os bens empregados como elementos necessários ao processo produtivo. Incluiriam nesta calcgoria, portanto, tanto a terra, o crédito, a moeda, quanıo os imóveis cm suas mais diversas espécies. A classilïação de bens de consumo ou de produção, lundada na destinação, independe da estrutura interna do bem em si, conforme explica o jurista.

Quanto aos bens de produção, sua função social não indicaria restrições de uso, fruição e disposição, ou scja, não se confundiriam com os limites negativos do dircito de propricdade. Diferentemente, significaria um poder "de dar ao objeto da propriedade destino determinado, de vinculá-lo a certo objetivo. O adjetivo social mostra que esse objetivo corresponde ao interesse coletivo e não ao interesse próprio do dominus; o que não-significa que não possa haver harmonização entre um e outro" t)

Esta idéia de função social como criadora de um poder-dever ao proprictário teria, portanto, um sentido positivo, consistente na idéia de colaboração) do proprictário, por meio de seu bem, à consecução dos interesses da socicdade.

40. Comparato, op. cil., p. 75. 
Mais tarde, Salomão Filho, em intertextualidade, assevera que "a classificação bens de consumo/bens de produção não esgota, no entanto, a variedade de bens que podem estar sujeitos a aplicą̧ø̃es várias do princípio da função social. Existem também os chamados bens de acesso, i. e., bens cuja utilização depende da possibilidade de poder concorrer naquele mercado" " Haveria, assim, ao lado dos bens de produção e dos bens de consumo, um tertius genus, formado pelos bens de acesso.

Quanto aos bens de acesso, a função social adquiriria contornos mais marcantes, implicando mais sérias limitações ao dircito de propriedade, dentre as quais se inclui a obrigatoriedade do compartilhamento das dimensões, físicas ou imateriais, do bem. Esta função social se realizaria ou pela co-propriedade desses bens ou pela garantia de acesso, através da restrição do dircito de propriedade de titular da rede.

Interessante notar é que a idéia de bens de acesso parece forjada exalamente para atacar a problemática que envolve as redes de inlira-estrutura, especialmente no Direito Econômico. Veja-se que Salomão Filho praticamente se vale das expressões "bens de acesso" e "redes de infra-estrulura" como sinônimos cm diversos trechos.

No entanto, não parece adequado igualar a função social das redes de infra-estrutura à lunção social de bens de acesso. Ainda que não laça grande diferença ao Dircito Econômico, a função social das redes de infra-estrutura ć muito mais ampla numa visão multidisciplinar do Direito, não se esgotando na função social de um mero bem de acesso, que implica, vale dizer, a obrigatoricdade de se compartilhar a infraestrulura com outros agentes de mercado que dela necessitem para exercer atividade cconômica (livre-iniciativa) ou para se manter no mercado $\mathrm{em}$ condição de isonomia a outros agentes (livre-concorrência).

Isso não-obstante, voltando aos bens de acesso, estritamente, verilica-se que sua função social realiza-se com o compartilhamento do bem. Por exemplo, no caso da Lei Geral de Telecomunicações brasileira, em vista de seu art. 73, a função social se percebe na hipótese de o prestador de serviços de telecomunicações, de caráter coletivo, poder exigir a utilização de infra-estrutura de outros prestadores de serviços públicos, por exemplo, de gás, cnergia ou rodovias (compartilhamento externo); ou mesmo infra-estrutura de prestadores de telecomunicações de interesse colctivo (compartillhamento interno).

Em última instância, tal idćia de lunção social, expressão clara do dirigismo estatal, acaba por se ligar à defesa do consumidor, na medida $\mathrm{cm}$ que permite, 
entre outras vantagens, a possibilidade de escolha de prestadores de serviços e a redução indireta do preço dos serviços por aumento da olerta.

Enlïm, o princípio da lunção social sobre os bens de acesso, na visão de Salomão Filho, atingc o dircito de propricdade $\mathrm{cm}$ scus três aspectos, ou scja, como direito de usar, fruir e dispor de um bem. Tanto é assim que o autor menciona, a lílulo de exemplo, a impossibilidade de se alienar uma rede de inlira-estrutura sem autorização do órgão regulador. ${ }^{+2}$

Não se pode olvidar apenas - reilere-se - que a função social das redes de infra-estrulura como bens de acesso e na área do Direito Econômico não- esgota as implicações jurídicas da função social dessas mesmas redes, conlorme se viu acima. Necessário, ainda, acenar às lunções sociais dos bens públicós e da cidade.

\subsection{Função social dos bens puiblicos}

Notadamente a partir da Constituição, de 1988, do Estatuto da Cidade c do Novo Código Civil, o que se tcm visto ć a proliferaçã̃o da função social como qualificativo de diversos institutos jurídicos. Nessa csıcira, é inegável que a propricdade tenha sido mais amplamente atingida, independentemente de suas classilicações. Foi por aí que despontaram as discussões sobre a função social do patrimônio público e, mais recentemente, das cidades, além das já supramencionadas.

Quanto aos bens públicos, loi Di Pietro ${ }^{\sqrt{3}}$ quem mais valorizou uma discussão sobre o signilicado c os limites de suas lunções sociais, levando $\mathrm{cm}$ conta a lipologia adotada pelo Código Civil de bens públicos como bens de uso comum, bens de uso especial (categorias que constiluem o domínio público do Estado) e bens dominicais (do domínio privado do Estado).

Explica a eminente administrativista que a discussão sobre a função social se concentrou sobre os bens de propriedade privada $\mathrm{cm}$ razão da existência de um conllito entre interesse privado e público a eles inerente. Já quanto aos bens públicos, a ausência desse conflito alastou semelhante discussão, do que não se deve depreender, todavia, que a propriedade pública esteja desobrigada a seguir ou alcançar uma lunção social, ainda que de modo e em limites dilerentes aos relativos à propriedade privada.

Pelo contrário, a idéia de lunção social é inerente aos bens públicos. Tanto é assim que, há certa época, era tomentoso accitar a titularidade do Estado

42. Op. cit., p. 70. Ver, a respeito, a Lei Geral de Telecomunicaçōes, art. I0I.

43. V. A gestão jurídica do parimônio imobilicirio do Poder Público, p. 57. 
como pessoa jurídica sobre os bens públicos de tão vinculados que estavam a um uso ou uma lïnalidade pública e social. Afectados ao uso do povo ou a uṇ serviço público, os bens do domínio público estatal cram tidos em si mesmos como uma função social.

Hoje, ainda, a lunção social dos bens componentes do domínio público estatal deriva imediatamente da aleclação desses hens. Note-se, porém, que a alelação a um lim público não os impede de ser objeto de outros tipos de utilização, inclusive de modo privativo e por particulares especílicos, desde que de modo compatível com linalidade precípua do bem. Aliás, a pluralidade de usos é, muitas vezes, uma lorma de maximizar as vantagens sociais que o bem pode lornecer.

Veja-se, nesse momento, como a questão do acesso necessário às redes de infra-cstrutura, suscitada por Salomão Filho, justifica que se thes confira um caráter quase-público. Se todas as redes guardassem essa nalureza jurídica, seria perfeitamente possível conciliar e adequar as diversas lormas de uso sobre elas, valendo-se de mecanismos de outorga, com maior ou menor precariedade, para dilerentes usos.

A despeito dessa discussão, note-se apenas que os bens dominicalis lambém desempenham uma lunçĩo social, mass não em si, como os bens do domínio público. Os dominicais, que constituem o domínio privado estatal, podem ser objeto de relações privadas e dentro de objetivos meramente patrimoniais, sujeitando-se, $\mathrm{cm}$ regra, a um regime de dircito privado. ${ }^{4+}$ Dessa forma, a lunção social que os vincula e orienta ć, scm qualquer óbice, a que as normas constitucionais c a legislação ordinária apontam, notadamente, sobre imóveis urbanos c rurais. ${ }^{45}$

\subsection{Funçóes sociais da cidade e fiunşão social de redes de infra-estrutura}

Após esses abreviados e perlunctórios comentários sobre algumas variações da lunção social da propriedade, perquirir em que medida as redes de inlracstrutura estão obrigadas a uma função social torna-se mais lácil.

Sabendo-se, pois, se são objetos de propriedade privada ou pública, se são bens de produção e se são bens de acesso, alguns indicativos sobre sua função social estarão postos. Daí se poderá aduzir quais funções sociais que as orientam, restando em aberto, porém, o conteúdo dessa somatória de lunções sociais.

44. Diga-se bem, regime privado parcialmente derrogado, hajja vista as disposiçóes dos ants. 100 e 191. parágraló único, da Constituição da Repúblicat contre outros dispositivos infraconstilucionais.

45. Nesse sentido, Dı PIETro (ibidem. p. 59) observa (jue o art. 188 da Constituição da República, de 1988, delermina, inclusive, gue os imóveis rurais públicos sejam adépuados à política agricola e de reforma agrária. 
Ora, constatou Milton Santos que, hoje, "a montagem das redes supõe uma antevisão das funções que poderão exercer e isso tanto inclui a sua forma material, como as suas regras de gestão"46. Com isso se quer dizer que as redes servem a uma lógica produtiva/circulatória preconcebida, o que, de pronto, já confirma que absorvem o papel de bens de produção.

Ademais disso, por suas características concretas, geográficas e funcionais, essas redes são meios necessários não-somente à produção e à circulação dos bens e serviços daqueles que as possui. Como meios, as redes concentram uma utilidade social e empresarial que ultrapassa a esfera de atuação privativa de seus proprietários. São, portanto, bens de produção também para aqueles que não as possuem e, por isso, convencionou-se designá-las, em algumas hipóteses, como bens de acesso.

Em terceiro lugar, as redes de infra-estrutura são, em sua grande maioria, bens públicos de uso especial, uma vez que se vinculam à prestação de serviços públicos. Delegados esses serviços, notadamente por meio das concessões celebradas após o programa de desestatização, da década de 1990, as redes, administradas, ampliadas ou reconstruídas por particulares, assumem a posição de bens reversíveis, mantendo-se apegadas às funções sociais inerentes aos bens de uso especial.

Por fim, resta saber se as redes guardam relação com as funções sociais da cidade, ${ }^{47}$ expressão cunhada no art. 182 , caput, da Constituição.

Preleciona Saule Júnior ${ }^{48}$ que as funções sociais da cidade envolvem interesses difusos, já que atingem diversas classes e categorias de pessoas que nela vivem e convivem. Por conseqüência, são funções igualmente indivisíveis, pois apenas se realizam quando condições de vida digna, justiça social e redução de desigualdades sociais sejam alcançados para todos os cidadãos, indistintamente.

Caracterizariam a realização plena dessas funções, o pleno acesso dos habitantes à moradia, lazer, saúde, educação, saneamento transporte público, segurança etc. Exatamente nesse caminho, coloca-se a prescrição da Constituição do Estado do Rio de Janeiro contida no art. 229, a saber: "as funções sociais da cidade são compreendidas como o direito de todo o cidadão de acesso à moradia, transporte público, energia elétrica, gás canalizado, abastecimento, iluminação pública, saúde, educação,

46. Op., cit. p. 265.

47. CorrêA, Roberto Lobato. O espaļ̧o urbano. São Paulo: Ática, 1995. Para o urbanisıno, a cidade é o lugar onde as diversas classes sociais vivem e se reproduzem. Tal termo, porém, carece de definição jurídica expressa. Explica o autor que a cidade, captada en múltiplas perspectivas, demonstra-se fragmentada, articulada, reflexo e condicionante social, p. 09.

48. Novas perspectivas do direito urbanístico brasileiro. Ordenamento constitucional da política urbana. Aplicaçāo e efićácia do plano-diretor. Porto Alegre: Sergio Antonio Fabris, 1997, p. 60. 
cultura creche, lazer, água potável, coleta de lixo, drenagem das vias de circulação, contenção de encostas; segurança e preservação do patrimônio ambiental e cultural"

A redação da norma constitucional estadual realça muito claramente, ainda que implicitamente, a imprescindibilidade das redes de infra-estrutura à concretização das funções sociais da cidade. ${ }^{49}$ Por isso mesmo, as redes devem-se incluir nessas funções, deixando-se guiar por elas em respeito à supremacia dos interesses da coletividade.

Em outras palavras, as redes de infra-estrutura absorvem uma relação de conformação com a cidade a partir do momento em que se fixam ao espaço urbano. As redes condicionam o espaço da cidade e são por ele condicionadas, numa relação mútua. ${ }^{50}$ Tanto é assim que o próprio Código Tributário Nacional baseou-se na existência de redes de infra-estrutura para reconhecer se determinado espaço participa da zona urbana, permitindo a incidência do IPTU (art. 32).

No entanto, pela própria força do dispositivo constitucional que consagra as funções sociais da cidade, e pelo alto valor que impregna os interesses difusos dos cidadãos quanto a essas funções, a relação de condicionamento que deve prevalecer, no devido termo, é a que põe as redes a serviço das cidades.

Enfim, por tudo isso, ponderadas as funções sociais acima aduzidas, constata-se em apertada síntese que: 1) toda rede de infra-estrutura, pública ou privada, deve seguir uma função social; 2) toda rede, pública ou privada, embutida no processo produtivo, sujeita-se à função social dos bens de produção; 3 ) toda rede vinculada a um serviço público segue a função social inerente ao patrimônio público; e 4) toda rede, pública ou privada, independentemente de sua localização espacial, desde que imprescindível a determinados serviços e atividades de interesse público, deve colaborar à consecução e manutenção das funções sociais da cidade.

\section{Conclusão: intervenção estatal e redes de infra-estrutura}

Em vista das duas abordagens empreendidas, permite-se concluir que a problemática jurídico-social referente às redes de infra-estrutura parece requisitar um

49. A função social da cidade, em nosso sentir, é o resultado de um conjunto de funções sociais, notadamente da função social da propriedade imóvel urbana. Seria a somatória da função social dos bens públicos e privados, de produção e de acesso, que se completaria, em direção aos princípios constitucionais do Estado brasileiro, com a função social das relações privadas, especialmente contratuais.

50. Segundo CORRÊA (ibidem, pp. 8-9), "o condicionamento [das cidades] se dá através do papel que as obras fixadas pelo homem, as formus espaciais, desempenham na reproduçäo das condiçöes de produșäo e das relações de produção...". 
mínimo de intervenção por parte do Poder Público sobre a criação, a manutenção, o funcionamento e as finalidades desses bens, especialmente na esfera local e urbana.

Questiona-se, porém, se a vinculação das redes de infra-estrutura a inúmeras variantes da função social da propriedade não-bastaria, por si, para abafar a conflituosidade que esses objetos polarizam.

Acredita-se, todavia, que a simples sujeição à função social da propriedade não é solução capaz de neutralizar, satisfatoriamente, as radiações sociais das redes em virtude da inexistência de um conteúdo certo e fechado imputável àquela expressão (função social).

A respeito, Del Nero já constatava que se desconhece, na jurisprudência, na doutrina e no Direito positivo, uma conclusão uniforme sobre quais sejam os efeitos jurídicos da expressão "função social da propriedade". Não se sabe se a propriedade é uma função social, se encontra fundamento filosófico em uma função social ou se, simplesmente, deve atender a certos requisitos legais, aos quais se convenciona reportar como requisitos de cumprimento de função social..$^{51}$

Essa incerteza geral levou o civilista a propor uma análise funcional e pragmática da expressão em comento, que redunda, em última análise, na hermenêutica dos dispositivos que dela tratam - tal como os arts. 5", 170, 184 e 186 da Constituição da República de 1988.

Uma análise funcional da função social da propriedade requer uma atividade hermenêutica sobre o tipo de eficácia das normas em que essa expressão está contida. Assim, por exemplo, valendo-se da categorização de José Afonso da Silva, a função social variaria de acordo com uma norma de eficácia plena, contida ou limitada.

Como a função social da propriedade em geral está prevista em normas constitucionais de eficácia limitada, ${ }^{52}$ não-basta remeter as redes de infra-estrutura a uma ou mais funções sociais, crendo que daí, automaticamente, surgirá um regime jurídico, um conjunto de prerrogativas e sujeições jurídicas que permeie esses bens. ${ }^{53}$

51. Op., cit., p. 79.

52. Excepcionalmente, a Constituição Federal, por via da redação do art. 186, que revela norma de eficácia plena, deu conteúdo jurídico certo à função social da propriedade rural. Os objetos de propriedade, principalmente móveis, por constarem da disposição geral dos arts. quinto e 170, normas de eficácia limitada, praticamente não produzem efeitos práticos sobre o exercício do direito de propriedade.

53. Quanto à ineficácia da obrigatoriedade de vinculação das redes a uma função social, vazia de conteúdo, SALOmão FiLho observa que o fato de o Regulamento Geral de Interconexão, Resolução ANATEL n. 40/98, ter declarado o caráter quase-público das redes e de ter determinado que deverão se organizar como vias de livre circulação em respeito à sua função social, não parece ter resolvido o problema no setor de telecomunicações brasileiro (ibidem, p. 57). Isto porque a obrigatoriedade de permissão de acesso 
O conteúdo da função social, mais ainda com a Constituição de 1988, restou mais vago, aberto, uma vez prevista a expressão em normas de eficácia limitada. Em nome de maior segurança jurídica e de disciplina infraconstitucional mais minuciosa, flexível e específica aos tipos de bens, largou-se aos entes políticos, no exercício de suas competências normativas, a tarefa de determinar um conteúdo à expressão.

Por essa razão, a idéia de função social mais se aproximou de uma espécie, ou espécies, de manifestação do poder de polícia do Estado. A função social, como preceito constitucional, revela-se pela atuação normativa, lato sensu, de cada ente político, imputando-lhes, por isso, um ônus político (de criar e fazer cumprir limitações administrativas).

Resumindo: se, de um lado, a função social com preceito constitucional de eficácia limitada (art. 5", XXIII, e 170, III) abriu espaço para a criatividade do Poder Público na elaboração de mecanismos efetivos de controle e fiscalização dos objetos da propriedade, como expressões do poder de polícia; de outro, essa ausência de parâmetros constitucionais mínimos quanto ao conteúdo da expressão igualmente gerou um ônus político para o Poder Público, o que compromete, principalmente nos Municípios, a concretização desta função social ou por falta da elaboração e imposição de limitações administrativas, sempre impopulares, ou pela relutância dos proprietários das redes os quais, muitas vezes, tem mais poder econômico e político que o Poder Público local.

Além disso, dentro do sistema constitucional atual, deve-se advertir que a conformação do conteúdo da função social das propriedades não pode prescindir de dois requisitos: (1) que, dentro da esfera do ente político responsável, esteja inserida dentro de um planejamento unitário, multidisciplinar, que relacione a tutela dos mais diversos bens jurídicos afetados pela propriedade, notadamente o meio ambiente, os direitos do consumidor, a defesa da livre-iniciativa e da livre-concorrência, a segurança e a qualidade de vida do cidadão e (2) que esteja adequada, concatenada com os preceitos reguladores dos outros entes políticos da federação, criando efetivamente um padrão de disciplina jurídica completo e cooperativo, direcionando aos fins públicos. ${ }^{54}$

(livre acesso) esbarra no direito de livre negociação. Assim, só se resolveria a solução, conforme o professor, pela "aplicaf̧ão de um bom nivel de dirigismo estatal" ibidem, p. 56.

54. Ricardo Toledo SILva afirma que "as estruturas institucionais de planejamento metropolitano $e$ de gestäo integrada de recursos hidricos, em articulação com as outras instâncias reguladoras de conte supra-setorial, emergem como instâncias legítimas e eficazes para regular as importantes dimensões sociais, físico-territoriais e ambientais dos sistemas de infra-estrutura, à parte as regras de organizaçã̃o) comercial dos servifos, às quais se dedicam de forma predominante os incipientes sistemas de regulação) setorial até agora criados". V. Infra-estrutura urbana. 
Tomando por base essas rasas observações, a intervenção do Estado na propriedade das redes de infra-estrutura, especificamente, realizar-se-ia com a limitação e o condicionamento ao exercício dos direitos de usar, fruir e dispor dessas coisas coletivas, impondo a seus detentores obrigações de fazer e não-fazer.

Tais limitações dependerão de uma concepção de quais requisitos compõem, concreta e especificamente, a função social dessas redes, levando-se em conta, pela própria natureza do objeto, uma relação necessária de pertinência com a função social dos bens de produção, dos bens de acesso, dos bens públicos, quando for o caso, e com as funções sociais da cidade. Dependerão, outrossim, da coragem e competência do Poder Público, bem como de seu planejamento e suas relações de comunicação e cooperação com outras esferas políticas - pois só assim poderá ser forjado um regime jurídico sobre as variadas implicações das redes (ambientais, urbanísticas, criminais, internacionais e econômicas).

Esse é o início de um caminho jurídico e político que se mostra apto a domar as complexidades das redes de infra-estrutura, assimétricas, reais e virtuais, locais e globais, controlando a potencialidade de conflitos que elas geram e, o que é mais importante, protegendo contra qualquer condicionamento social indesejado que elas imponham àqueles que, na verdade, delas deveriam se servir.

São Paulo/Presidente Prudente, junho de 2003. 


\section{Referências bibliográficas}

Brownlie, Ian. Princípios de direito internacional público, $4^{a}$ ed. Tradução portuguesa. Lisboa: Fundação Calouste Gulbenkian, 1997.

CAHAlI, Yussef Said. Responsabilidade civil do Estado. São Paulo: Malheiros, 1985.

CARdoso, Luiz Reinaldo de Azevedo. Plano diretor e infra-estrutura urbana. Revista CEPAM, São Paulo, v. 1, n. 2, pp. 25-28, abril-junho, 1990.

CASTElls, Manuel. A sociedade em rede. In A era da informação: economia, sociedade e cultura, São Paulo: Paz e Terra, 2002.

Comparato, Fábio Konder. A função social dos bens de produção. Revista de Direito Mercantil, Industrial, Econômico e Financeiro, n. 63, pp. 72-79, julho-setembro, 1986.

CORRÊA, Roberto Lobato. O espaço urbano. São Paulo: Ática, 1995.

Del NERo, João Alberto Schützer. O significado jurídico da expressão "função social da propriedade" Revista da Faculdade de Direito São Bernardo do Campo, v. 3, pp. 79-97, 1997.

Dı Pietro, Maria Sylvia Zanella. A gestão jurídica do patrimônio imobiliário do Poder Público. Cadernos FUNDAP, São Paulo, ano 09, n. 17, dezembro, 1989, pp. 55-66.

Dı PIEtro, Maria Sylvia Zanella. Parcerias na administração pública. São Paulo: Atlas, 2002.

FIGUEIREDo, Lúcia Valle. O devido processo legal e a responsabilidade do Estado por dano decorrente do planejamento. Revista Diálogo Jurídico, Salvador: CAJ - Centro de Atualização Jurídiça, n. 13, abril-maio, 2002. Disponível na Internet: http:// www.direitopublico.com.br. Acessado em 10 de junho de 2003.

MARQUes NeTo, Floriano de Azevedo. A nova regulação dos serviços públicos. RDA, Rio de Janeiro: Renovar, v. 228, abril-junho, 2002, p. 19.

MEDAUAR, Odete. Regulação e auto-regulação. RDA, Rio de Janeiro: Renovar, v. 228, abril-junho, 2002, p. 123-128.

Milaré, Édis. Direito do ambiente. São Paulo: Revista dos Tribunais, 2001.

PITOFSKy, Robert et alli. The essential facilities under U.S. Antitrust Law" Antitrust Law Journal, v. 70, 2002, pp. 443-462.

RANDALL, Kenneth. C. Universal jurisdiction under international law. Texas Law Review, março, 1988, pp. 785-841.

Salomão Filho, Calixto. Regulação da atividade econômica - princípios e fundamentos jurídicos. São Paulo: Malheiros, 2001.

SANTOS, Milton. A natureza do espaço: técnica e tempo, razão e emoção. São Paulo : Edusp, 2002.

SAULE JÚNIOR, Nelson. Novas perspectivas do direito urbanístico brasileiro. Ordenamento constitucional da política urbana. Aplicação e eficácia do plano diretor. Porto Alegre: Sergio Antonio Fabris, 1997. 
SiLvı, Ricardo Toledo. Infra-estrutura urbana, necessidades sociais e regulação pública. Documento disponível na página eletrônica do Instituto de Pós-Graduação em Planejamento Urbano e Regional da Universidade Federal do Rio de Janeiro, http:/ /www.ippur.ufrj.br/observatorio, acessado em 10 de junho de 2003.

Silva, Ricardo Toledo. Público e privado na oferta de infra-estrutura urbana no Brasil. Documento referente ao Dossiê Serviços urbanos, cidade e cidadania, do Programa Interdisciplinar sobre Globalização Econômica e Direitos no Mercosul GEDIM), disponível na página eletrônica da Faculdade de Arquitetura e Urbanismo da Universidade de São Paulo, www.usp.br/fau. 